\title{
Resenha crítica do livro "Avaliação: políticas educacionais e reformas da educação superior", de José Dias Sobrinho - para um debate atual da avaliação da educação superior no Brasil
}

Resenhado por: Janaina Ferreira $\mathrm{Ma}^{1}$

SOBRINHO, J. D. Avaliação: políticas educacionais e reformas da educação superior. São Paulo: Editora Cortez, 2003.

Esta resenha tem por objetivo fazer uma reflexão sobre o livro "Avaliação: políticas educacionais e reformas da educação superior" (2003), de José Dias Sobrinho, destacando suas principais contribuições e sua atualidade, tendo em vista o caminho percorrido pelas políticas de avaliação da educação superior no Brasil nos últimos onze anos (2004-2015).

O Sistema Nacional de Avaliação da Educação Superior (Sinaes), instituído pela Lei $n^{\circ} 10.861$ de 14 de abril de 2004, no início do primeiro mandato do ex-presidente Luiz Inácio Lula da Silva, completou dez anos recentemente. Conforme foi implementado, o Sinaes adquiriu paulatina importância para as políticas de educação superior do Ministério da Educação (MEC), em especial para as de regulação, expansão e financiamento, tornando-se a política de maior regularidade e penetração na vida das Instituições de Educação Superior (IES) brasileiras.

As bases constituintes da Lei que instituiu o Sinaes (Lei 10.861) foram dadas no documento elaborado pela Comissão Especial de Avaliação (CEA) do Ministério da Educação (MEC), sendo que muitos dos seus membros foram protagonistas da criação da Revista Avaliação (Campinas; Sorocaba)². A leitura da revista é importante para compreender os fundamentos do sistema, bem como as concepções, posicionamentos e contradições presentes no debate da

\footnotetext{
1 Pesquisadora-tecnologista do Instituto Nacional de Estudos e Pesquisas Educacionais (Inep), vinculada à Diretoria de Avaliação da Educação Superior (Daes). Mestre e bacharel em Administração, ambos pela Universidade Federal da Bahia (UFBA). Tem interesse em pesquisas nas áreas de Políticas Públicas em educação superior, Tecnologias de Informação e Comunicação, Estudos Organizacionais e Ensino e Pesquisa em Administração. Contato: janaina.ma@inep.gov.br

${ }_{2}$ A Revista começou a ser publicada em 1996, inicialmente pela Rede de Avaliação Institucional da Educação Superior (RAIES); a partir de 2007 é publicada em parceria com a Universidade de Sorocaba (Uniso).
} 
avaliação da educação superior no país, vigentes no período anterior à mencionada Lei.

É fato que, após a sua instituição, o Sinaes passou por diversas alterações, o que gera a necessidade de uma reflexão acurada sobre os avanços do sistema, bem como uma análise de quais desafios prevalecem. Nessa linha, e visando debater a política de avaliação da educação superior em diversas dimensões, algumas instituições e entidades, como o Fórum de Pró-reitores de Graduação (FORGRAD), a Comissão de Educação da Câmara dos Deputados e o próprio Instituo Nacional de Estudos e Pesquisas Educacionais Anísio Teixeira (Inep) ${ }^{3}$, promoveram, durante o ano de 2014, eventos que reuniram especialistas, acadêmicos e entidades representativas de instituições para debater o Sinaes.

Neste contexto, a obra de José Dias Sobrinho aqui resenhada é, ao mesmo tempo, um marco e uma referência na história da avaliação da educação superior do Brasil, tanto pela qualidade da pesquisa acadêmica do autor na área, quanto por sua participação direta na construção dessa história. De maneira resumida, vale lembrar que o professor Dias Sobrinho dedica-se, há mais de meio século, à educação superior, tendo sido pró-reitor de pósgraduação da Unicamp (1990-1994), de onde conduziu a primeira avaliação institucional do país, utilizada como referência para o Programa de Avaliação Institucional das Universidades Brasileiras (Paiub). Além disso, o professor Dias Sobrinho foi o presidente da Comissão Especial de Avaliação (CEA) do MEC, bem como membro da Comissão Nacional de Avaliação da Educação Superior (Conaes).

Sua obra traz livros como "Avaliação da Educação Superior" (2000) e "Universidade e Avaliação: Entre a Ética e o Mercado" (2002). Nesta resenha, porém, destacamos "Avaliação: políticas educacionais e reformas da educação superior" (2003) que, além de recuperar um pouco da experiência anterior do

\footnotetext{
${ }^{3} \mathrm{O}$ Inep é uma autarquia federal, vinculada ao Ministério da Educação, que tem, dentre suas finalidades, coordenar o processo de avaliação dos cursos de graduação, em conformidade com a legislação vigente. Em 2014, por meio da Diretoria de Avaliação da Educação Superior (DAES), o Instituto mobilizou esforços para estimular não apenas reflexões acerca do que foi produzido nesta primeira década do Sinaes, mas também para identificar quais desafios 0 sistema tem à frente nos próximos anos.
} 
autor na UNICAMP e no PAIUB, constitui-se num esforço singular de demarcação das fronteiras epistemológicas, ontológicas e metodológicas, nas quais o tema da avaliação da educação superior transita e se desenvolve.

Esta resenha é, portanto, um convite a uma releitura do mais consagrado autor brasileiro na área de avaliação da educação superior, buscando refletir não só sobre a contemporaneidade de sua análise crítica sobre o tema, mas especialmente sobre em que medida o país avançou, bem como os participantes de seu complexo sistema de educação superior, rumo a uma avaliação com propósitos efetivamente educativos, tal como defendida pelo autor na obra em questão.

O livro "Avaliação: políticas educacionais e reformas da educação superior" foi publicado no ano que antecedeu a publicação da Lei que instituiu o Sinaes - momento em que o professor Dias Sobrinho era presidente da Comissão Especial de Avaliação da Secretaria de Educação Superior do Ministério da Educação (SESU/MEC). O livro está organizado em cinco capítulos, que se complementam e se reforçam, corroborando a ideia de que a avaliação produz efeitos sociais, sendo um instrumento de poder dos Estados e cujos efeitos são vinculados a concepções de mundo.

O primeiro capítulo apresenta uma breve história da avaliação e um panorama geral dos seus diversos enfoques, buscando resgatar "as características mais importantes e que melhor explicam as contradições e a complexidade do campo da avaliação" (p. 29). Todo o esforço feito pelo autor tem como objetivo, dentre outros, mostrar que o tema avaliação, sua definição, seus objetivos, seus métodos, seus públicos, ou ainda, sua lógica, conforma-se e se delineia a partir de posições éticas, políticas e ideológicas definidas. Fica claro que somente a partir de uma contextualização é possível compreender os diversos enfoques e pressupostos metodológicos relacionados à avaliação ao longo do tempo.

No segundo capítulo, o autor analisa como a avaliação se constituiu em instrumento central das reformas da educação superior, apresentando inicialmente a constituição desse fenômeno nos Estados Unidos e na Inglaterra para, em seguida, tratar da experiência brasileira. O autor explica como o 
surgimento do Estado avaliador está relacionado à complexificação e ampliação das demandas por educação, agravada pelas restrições econômicas e, dessa forma, como a partir dos anos de 1960, nos Estados Unidos, na GrãBretanha e demais países industrializados, a avaliação passou a fazer parte essencial das agendas e estratégias governamentais.

O problema destacado é que a tentativa de controlar os gastos e acompanhar o sucesso das políticas oficiais faz surgir uma avaliação que prima pela busca da eficiência, tal como entendida e perseguida por uma empresa privada com vistas ao lucro. Nessa passagem do Estado-providência para o Estado-interventor, a avaliação se configura como predominantemente controladora e organizadora das políticas de distribuição de recursos do Estado. "Em geral, são avaliações externas, somativas, orientadas para o exame de resultados, realizadas ex post e seguem prioritariamente os paradigmas objetivistas e quantitativistas" (p. 60).

Dias Sobrinho mostra como, no Brasil de 2003, conviviam dois distintos modelos de avaliação: o Exame Nacional de Cursos (ENC), complementado pela Análise das Condições de Ensino (ACE) e o Programa de Avaliação Institucional das Universidades Brasileiras (Paiub). Num exercício de classificação dos dois modelos, Dias Sobrinho explica como o ENC enquadrase no paradigma positivista, com predominância de métodos objetivistas e interesse nos resultados, enquanto o Paiub tem mais afinidade com 0 paradigma subjetivista e métodos qualitativos e participativos. $\mathrm{O}$ autor reforça a necessidade de eliminar a polaridade entre os enfoques e trabalhar com a sua complementaridade para dar conta da complexa realidade. Lamenta ainda que, no âmbito das reformas e das avaliações de educação superior das décadas de 1970 a 1990, tenha prevalecido uma racionalidade utilitária, que impõe ao universo da educação uma lógica econômica, baseada em critérios de eficiência.

No terceiro capítulo, partindo da premissa que a avaliação produz efeitos e é eminentemente política e de amplo interesse social, o autor faz uma reflexão sobre os efeitos produzidos pela avaliação educacional a partir de dois enfoques: a avaliação tecnológica e a avaliação democrática. De maneira 
geral, o que se expõe neste capítulo é a consolidação das discussões apresentadas nos capítulos anteriores. A avaliação tecnológica é objetivista e quantitativista, voltada para a gestão, planejamento e controle. Nela, poucas pessoas decidem os objetivos que devem ser perseguidos por muitos. Utilizase de testes e exames em larga escala e se legitima pelo aparato tecnológico. Está ligada à ideia de uma sociedade mercantil e competitiva, guiada pela ética utilitarista. A avaliação democrática, por sua vez, está ligada a uma epistemologia subjetivista, participativa, que valoriza os processos de autoavaliação. A relação entre os participantes é de intersubjetividade e não de autoridade. Valoriza-se a experiência dos indivíduos e não há preocupação com a replicação dos métodos utilizados. Nessa perspectiva, a avaliação está a serviço do interesse público.

O quarto capítulo aborda a grande complexidade da avaliação da educação superior. "A avaliação é uma construção histórica, social, inserida nos núcleos do poder, portanto dinâmica e atravessada de contradições" ( $p$. 136). O autor aborda o caráter multidimensional e multifuncional da avaliação e discute como o crescimento de sua importância para a gestão pública conduziu à profissionalização da área, que deixa de ser apenas acadêmica para se configurar como fenômeno social e instrumento de poder. O que Dias Sobrinho reforça neste quarto capítulo é que a complexidade da avaliação da educação superior corresponde à complexidade das concepções de mundo. Neste contexto, define duas lógicas de avaliação, com dois sistemas de ideias e práticas contraditórias, porém não excludentes: a avaliação tecnoburocrática, vinculada a uma perspectiva empírico-racionalista, que ganha força a partir da década de 1960; e a avaliação formativa, autonomizante, crítica, democrática (dentre outras denominações recebidas), vinculada a uma perspectiva qualitativa, subjetiva e indutiva, que começa a crescer no final da década de 1960.

A crítica recai sobre o reducionismo do complexo fenômeno de avaliar a uma simples operação de medir e quantificar. A avaliação, assegura o autor, não deve assumir um papel de controle, sobrepondo-se aos próprios processos de aprendizagem, mas ser educativa e, portanto, contribuir para a 
compreensão do fenômeno educativo e de sua finalidade essencial, qual seja a formação no sentido pleno, a função da educação em sua significação maior. Nessa linha, a legitimação da avaliação conduzida pelas agências avaliadoras dos Estados não deve substituir as práticas e sentidos escolares da intencionalidade educativa.

No quinto e último capítulo, o autor encerra a obra reforçando as duas concepções paradigmáticas de avaliação: a mecanicista e a holística, e defendendo que a construção da qualidade requer a compreensão dos sentidos essenciais de uma instituição. A avaliação não se reduz a uma medida, ela é "um universo de significações abertas, que adquire força por meio da interatividade, da construção coletiva" (p.177), daí a importância de ser conduzida pelos próprios agentes da instituição.

Dias Sobrinho defende a avaliação institucional devendo ter como objeto central aos fins da instituição, sendo que o fim primordial de uma instituição educativa é a formação do estudante em seu sentido pleno. Ela pode produzir conhecimentos objetivos acerca da realidade, mas deve também investigar "os múltiplos sentidos que as práticas educativas estão construindo, em função da ideia central da formação" (p.181).

A maior importância dessa obra, passados doze anos de sua publicação, talvez seja a possibilidade de contrapor o que inicialmente era um modelo de avaliação a ser perseguido (a avaliação educativa), com o que de fato foi alcançado nesta direção. Assim, se por um lado o Sinaes se consolidou como a maior política de avaliação da educação superior do país, por outro também contribuiu para reforçar uma avaliação baseada no paradigma mecanicista justamente aquele que desejava superar.

Em face do exposto, o que dizer dos caminhos percorridos pelo Sinaes nestes mais de dez anos? Apesar dos esforços empreendidos no sentido de uma avaliação mais participativa, em que uma cultura de autoavaliação e de permanente busca pela qualidade da formação estejam presentes (o que tem sido bastante perseguido, especialmente pelo constante trabalho das Comissões Próprias de Avaliação - CPA), estudiosos da área mostram que a 
magnitude do sistema educacional tensionou a avaliação para o seu lado mais tecnoburocrático, mensurador e controlador.

O debate sobre a qualidade da educação superior no Brasil, tal como vem sendo difundido pela mídia e por uma parcela das instituições privadas, foi seduzido pela ideia de comparação e rankeamento, muito pertinentes à lógica mercantil, contribuindo para a consolidação dos indicadores estatísticos de qualidade ${ }^{4}$ e de uma atuação reguladora cada vez mais punitiva por parte do Estado.

Nesse sentido, a obra de Dias Sobrinho é extremamente provocadora e também perturbadora, pois convida a pensar sobre quais caminhos percorrer para que sejam promovidas e alcançadas as mudanças educacionais ensejadas para a educação superior, sem deixar que se percam as práticas e as reflexões formativas, que fomentam a liberdade e autonomia destas instituições. Mais ainda, o autor nos inspira a pesquisar de onde saem as vozes dissonantes do modelo de avaliação vigente, seus questionamentos e reflexões, suas práticas e suas proposições de melhoria e aprimoramento.

Nos anos recentes, revistas e livros mostram que muito conhecimento tem sido produzido/publicado por pesquisadores da área de avaliação da educação superior no Brasil. Mas qual tem sido o foco das críticas? E quantas conseguem, para além de 'denúncias' sobre as deficiências do modelo vigente, ser propositivas e apontar novos caminhos?

O acompanhamento rigoroso desse corpo de conhecimento produzido sobre o Sinaes, após seus quase onze anos, é fundamental para uma reflexão acurada sobre as inconsistências e necessidades de melhoria no interior das instituições de educação superior brasileira e, também, na própria prática educacional do setor.

A leitura de "Avaliação: políticas educacionais e reformas da educação superior" traz possibilidades de revigoramento do espírito crítico que permeia o

\footnotetext{
${ }^{4}$ De acordo com a Portaria Normativa $\mathrm{n}^{\circ} 40$ de 12 de dezembro de 2007, Art. 33-B, são indicadores de qualidade [...] de cursos superiores: o Conceito Preliminar de Curso (CPC), instituído pela Portaria Normativa $n^{\circ} 4$, de 05 de agosto de 2008; de instituições de educação superior: o Índice Geral de Cursos Avaliados da Instituição (IGC), instituído pela Portaria Normativa $n^{\circ}$ 12, de 05 de setembro de 2008; e de desempenho de estudantes: o conceito obtido a partir dos resultados do Enade.
} 
debate sobre a avaliação da educação superior, na expectativa de avanços rumo a processos avaliativos mais holísticos, públicos e educativos - algo que o professor Dias Sobrinho, tão elegantemente, conseguiu imprimir ao debate da avaliação da educação superior no Brasil.

\section{Referências}

BRASIL. Lei n. 10.861, de 14 de abril de 2004. Institui o Sistema Nacional de Avaliação da Educação Superior - SINAES e dá outras Providências. Diário Oficial da União, n. 72, de 15 de abril de 2004, Seção 1, p. 3-4.

BRASIL. Ministério da Educação. Portaria Normativa n. 40, de 12 de dezembro de 2007, republicada no Diário Oficial da União de 29 de dezembro de 2011, Seção 1, p. 23.

DIAS SOBRINHO, J. Avaliação da Educação Superior. Petrópolis: Vozes, 2000.

$\overline{\text { Insular, } 2002 .}$

. Universidade e Avaliação: entre a ética e o mercado. Florianópolis: 